\title{
СМЕНА «РДШ - ТЕРРИТОРИЯ САМОУПРАВЛЕНИЯ» В ВДЦ «ОРЛЁНОК» КАК ПРИМЕР ДЕЯТЕЛЬНОЙ СРЕДЫ ДЛЯ ФОРМИРОВАНИЯ ПРОЕКТНОГО МЫШЛЕНИЯ У ПОДРОСТКА
}

\section{THE SHIFT OF «RUSSIAN MOVEMENT OF SCHOOLCHILDREN - TERRITORY OF SELF- GOVERNMENT» IN RUSSIAN CHILDREN'S CENTER "ORLYONOK» AS AN EXAMPLE OF ACTIVITY ENVIRONMENT FOR THE FORMATION OF PROJECT-BASED MINDSET OF A TEENAGER}

\section{A. Rvachev}

Summary: The article describes the process of realization of the thematic shift «Russian movement of schoolchildren - Territory of selfgovernment» on the basis of Russian Children's Center «Orlyonok» in summer in 2019. «RosdetCenter» specialists and methodologists of the charity foundation «Captains» developed the thematic contents of the shift program collaboratively. The description of two shift program stages is presented: there are educational and design directions. On the example of one of the project stages, the general scheme of project teams' work within the shift is described. More detailed examples of project initiatives prepared by participants of the direction «Business Thinking» and the results of shift participants' work in this direction are presented.

Keywords: Russian Children's Center «Orlyonok», teenager, project-based mindset, project, business-oriented thinking, environmental approach.
$\mathrm{B}$ России в последние годы особую популярность приобрели различные федеральные конкурсы для школьников и студентов: «Мой первый бизнес», «РДШ - Территория самоуправления», «Большая перемена», «Цифровой прорыв», «Управляй», форумная компания «Росмолодёжи». Итогом конкурса для участника является тот или иной проект и возможность получить ценные призы, а для государственных структур реализация директивы президента о создании действующих социальных лифтов. Чаще всего итоги подобных конкурсов подводятся в режиме реального времени на различных лагерных площадках для школьников и форумных площадках для студентов.

В 2019 году 700 финалистов двух конкурсов «Мой первый бизнес» и «РДШ - Территория самоуправления» встретились в ВДЦ «Орлёнок» для акселерации проектов, с которыми ребята принимали участие в конкурсах и создания новых проектных инициатив. В составлении программы смены приняли участие специалисты отдела
Рвачев Алексей Сергеевич

Аспирант, Воронежский Государственный Педагогический

университет

rvachev.a@yandex.ru

Аннотация: В этом тексте дано описание процесса реализации тематической смены «РДШ - Территория самоуправления» на базе всероссийского детского центра «Орлёнок» летом 2019 года. Тематическое наполнение смены разрабатывали совместно специалисты «Росдетцентра» и методисты благотворительного фонда «Капитаны». Представлено описание двух этапов смены: образовательного и проектного. На примере одного из треков проектного этапа описана общая схема работы проектных команд в рамках смены. Более подробно представлены примеры проектных инициатив, подготовленных участниками трека «Предпринимательское мышление». Зафиксированы итоги трека в контексте инициации проектных инициатив участников смены.

Ключевые слова:

ВДЦ «Орлёнок», подросток, проектное мышление, проект, предпринимательское мышление, средовой подход.

по работе с ВДЦ ФГБУ «Росдетцентр» и методисты благотворительного фонда поддержки образовательных программ «Капитаны». Работа с участниками смены состояла из двух этапов.

Первый этап - «Азбука проектной деятельности» проходил в течении пяти дней и включал в себя пять тренингов: управление проектом, формирование личного бренда, дизайн презентации проекта, управление временем, основы SMM. Основная задача этапа сформировать у всех участников смены базовые представления о проекте, проектной команде и жизненном цикле проекта. Опираясь на исследование эволюции проектирования В.Л. Глазычева [1], можно сформулировать следующее определение: проектное мышление в широком смысле - это «внутренняя установка на расширение своего Я» посредством проектной деятельности, которая перестает быть элементом, обязательно встроенным в практику [2, с.29].

Успешность освоения материала проверяли в игро- 
вой форме. Участники выполняли задания, демонстрирующие уровень усвоение материала. Также каждый мастер направления ежедневно давал домашние задания. Ребята заинтересовавшись темой тренинга, могли более подробно разобраться в специфике направления. В первой части смены конкурсанты посещали занятия в своих командах, с которыми они приехали в ВДЦ «Орлёнок».

В рамках второго - проектного этапа участникам предложили распределиться по 14 образовательным направлениям: экология, добровольчество, ЗОЖ, военная патриотика, популяризация науки, «как найти свою экспертность?», игропрактика, предпринимательское мышление, лига ораторов, медиашкола, я - медиалидер, послы РДШ, урбанистика - дизайн общественного пространства, команда как форма самоуправления. Основная задача этапа - инициировать большинство участников смены как авторов и реализаторов проектных инициатив. Далее пять дней под руководством наставников в новообразованных коллективах участники смены создавали проектные инициативы одного из трёх заявленных уровней: уровень отряда, уровень лагеря, уровень тематической смены. Также эта градация предлагалась к применению для реализации этих проектов при возвращении из ВДЦ с небольшими поправками: уровень отряда - уровень школы, уровень лагеря - уровень города, уровень тематической смены -уровень всероссийской акции.

Принцип работы проектных команд первой и второй частей смены полностью повторяет в адаптированном для ВДЦ виде основные составляющие классического проектного акселератора. В программе присутствуют такие пункты как: менторство, обучение, ресурсная и экспертная поддержка. А вместо процента от прибыли реализованные проекты будут делиться с организаторами социальным капиталом.

По итогам работы трёх дней все образовательные направления приготовили для презентации экспертной комиссии набор проектных инициатив на каждый из трёх заявленных уровней. Примерно 50\% проектных инициатив были утверждены к реализации до конца смены на территории ВДЦ «Орлёнок». Остальные с комментариями экспертов были направлены на доработку.

Проекты уровня отряда и уровня лагеря после реализации оценивались участниками тестовой реализации. Впоследствии все результаты собирали в сводную таблицу, чтобы определить наиболее успешные проекты с точки зрения благополучателей. Проекты уровня тематической лагерной смены оценивались экспертным жюри. Определяли лучший проект для реализации тематической лагерной смены РДШ на будущий год.
На выходе все участники смены получили готовый паспорт проекта, комментарии экспертов и опыт практической реализации проектной инициативы. Все проектные инициативы были собраны организаторами в тематический сборник для распространения полученного опыта среди участников РДШ.

Теперь более подробно рассмотрим весь проектный цикл на примере одного из четырнадцати образовательных направлений. Трек предпринимательское мышление собрал в заявке больше всего участников смены. Этот факт объясняем участием в смене призёров конкурса «Мой первый бизнес». Ребята - участники трека в большинстве своём имели опыт реализации предпринимательского проекта. В большинстве случаев, в силу возраста, словосочетание «предпринимательский проект» трактовался ребятами как описанная идея. Без изготовления прототипа, тем более монетизации.

Рассмотрим примеры проектов образовательного направления «Предпринимательское мышление». Одной из целевых установок для участников смены в рамках этого направления была максимальная ориентация на реализацию проекта в городе проживания школьников по возвращении из ВДЦ.

\section{Фелеральный уровень}

Предполагалось, что проектные инициативы, успешно прошедшие процедуру публичной защиты, будут реализованы при поддержке оргкомитетов конкурсов «Мой первый бизнес» и «РДШ - Территория самоуправления» в новом учебном году. Рассмотрим более подробно примеры проектов:

- Челлендж - «Я-предприниматель». Варианты заданий в рамках челленджа: заработать конкретную сумму денег публично вести отчёт в социальных сетях; выбрать направление в бизнесе, которое хочется освоить и месяц заниматься этим делом, публично отчитываясь о своих успехах в социальной сети; записать 10 интервью с местными предпринимателями - описать их путь предпринимателя.

- Всероссийская акция - «Я у мамы предприниматель». Организация встреч старшеклассников с региональными представителями предпринимательского сообщества с обсуждением пути достижения успеха.

- Всероссийский Workshop - профориентационное мотивирующее мероприятие для школьников в формате питч-сессии их предпринимательских проектов с привлечением региональных представителей предпринимательского сообщества.

- Всероссийский предпринимательский квест профориентационное мотивирующее меропри- 
ятие для школьников в игровой форме, знакомящее с историями создания успешных бизнесов.

\section{Уровень субъекта Российской Федерации}

Предполагалось, что проектные инициативы, успешно прошедшие процедуру публичной защиты с пройденным тестом на территории ВДЦ при участии не менее трёх отрядов, будут реализованы при поддержке оргкомитетов конкурсов «Мой первый бизнес» и «РДШ - Территория самоуправления» в новом учебном году. Рассмотрим более подробно примеры проектов:

- Диалог на равных с бизнесом - организация встречи старшеклассников с представителями городского предпринимательского сообщества с обсуждением их пути к успеху.

- Городской кейс-турнир с реальными задачами к решению от представителей городского предпринимательского сообщества.

- Ярмарка проектов школьников и студентов. Презентация MVP предпринимательских проектов в формате стендовой сессии с привлечением потенциальных инвесторов из числа представителей городского предпринимательского сообщества.

\section{Уровень школы}

Предполагалось, что проектные инициативы, успешно прошедшие процедуру публичной защиты с пройденным тестом на территории ВДЦ при участии не менее одного отряда, будут реализованы при поддержке оргкомитетов конкурсов «Мой первый бизнес» и «РДШ - Территория самоуправления» в новом учебном году. Рассмотрим более подробно примеры проектов:

- Предпринимательская игра, моделирующая различные бизнес-процессы: заработок, инвестиции, переговоры, управление проектом.

- Предпринимательский мастер-класс, раскрывающий одну из актуальных тем в бизнесе: маркетинг, продажи, финансы.

- Просветительское мероприятие в формате рассказа от действующего предпринимателя о бизнес-трендах будущего.

После доработки проектов с экспертами процент проектных инициатив, допущенных до реализации на территории ВДЦ «Орлёнок» в рамках смены «РДШ - Территория самоуправления», вырос до 70\% от общей массы заявок.

Вернёмся к треку предпринимательское мышление и проанализируем успешность реализации проектных инициатив. Все проекты уровня школы были реализованы в тестовом формате и получили высокие оценки от участников. Два из трёх проектов уровня город были реализованы и получили высокие оценки от участников. Третий проект был направлен на доработку проектной документации и остановился на этапе разработки. Не один из проектов федерального уровня не был реализован в рамках смены в виде акции на весь ВДЦ «Орлёнок». Проектов смен в рамках этого образовательного направления предложено не было. Можно сказать, что врожденным проектным мышлением обладают прежде всего предприниматели, которых Й. Шумпетер трактовал как «нарушителей спокойствия», разрушителей традиционного уклада жизни: «...быть предпринимателем - значит делать не то, что делают другие... делать не так, как делают другие» [4, с. 199].

Считаем важным отметить тот факт, что за время смены почти все проектные команды смогли пройти полный проектный цикл от момента создания идеи до реализации проекта и получения внешней обратной связи от участников проекта. Стоит отметить, что часть проектов была реализована неудачно. Виной тому были как внешние обстоятельства (изменения в расписании деятельности лагеря участника проект) так и внутренние (неспособность команды подготовить необходимый реквизит). Итоговая финальная рефлексия внутри трека по итогам смены дала возможность наставникам обратить внимание участников смены на типичные ошибки при реализации проектов в заявленном направлении деятельности. Это позволяет нам утверждать, что процент типичных ошибок в будущем у этих проектных команд, при условии продолжения совместной работы, будет значительно ниже.

Негативным фактором в этой истории остаётся тот факт, что собранные за время смены «РДШ - Территория самоуправления» в ВДЦ «Орлёнок» команды в подавляющем большинстве не смогли сохранить свою целостность и с окончанием смены завершили своё существование. Субъекты проектной деятельности должны обладать не просто проектным мышлением, а проектной культурой, которая, согласно И.А. Колесниковой и М.П. Горчаковой-Сибирской, включает три составляющие: экологическую, концептуальную и аксиологическую [3], а для работы в команде крайне важен эмоциональный интеллект, понимаемый как способность управления эмоциями (своими и чужими). Завершение проекта в связи с окончанием жизненного цикла проектной команды - реалистичная концовка тематической смены по проектированию.

С началом нового учебного года все перечисленные проекты в том или ином виде были реализованы при поддержке оргкомитета конкурса «Мой первый бизнес». 


\section{ЛИТЕРАТУРА}

1. Глазычев В.Л. Лекция 06 эволюции проектирования. URL: http://www.shkp.ru/lib/archive/second/2001-1/8 (дата 0бращения 3.06.2020)

2. Товмасян В.В., Шихвердиев А.П., Оганезова Н.А. Проектное мышление: методологические основы // Вестник Научно-исследовательского центра корпоративного права, управления и венчурного инвестирования Сыктывкарского государственного университета. 2019. № 3 - С. 26-35

3. Колесникова И.А., Горчакова-Сибирская М.П. Педагогическое проектирование. М.: Издательский центр «Академия», 2005. 286 с.

4. Шумпетер Й. Теория экономического развития. М.: Прогресс, 1982. 456 с.

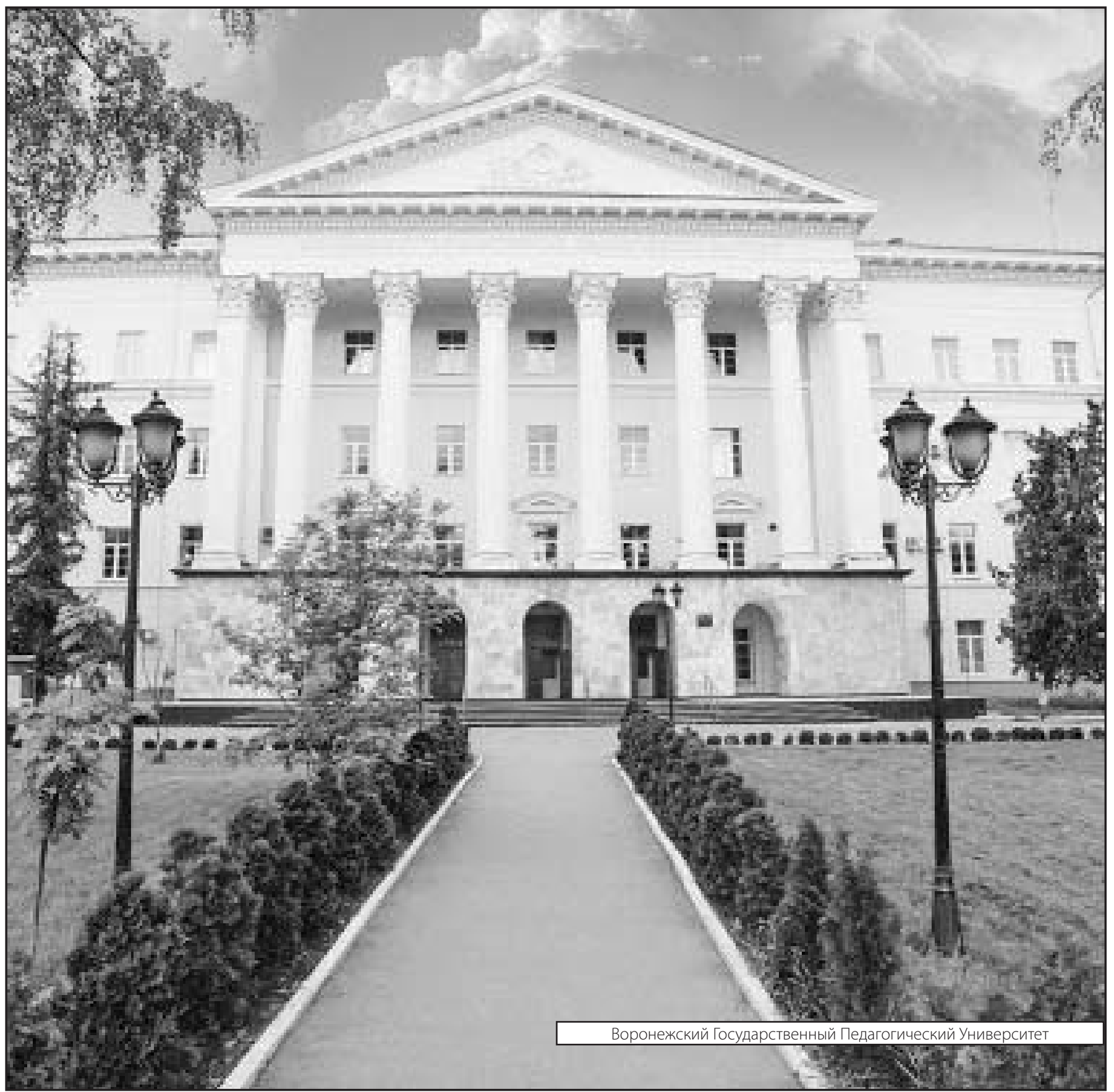

